\title{
Elucidation of Genetic Parameters Controlling Yield and Quality Traits in Rice (Oryza sativa L.)
}

\author{
S. Saravanan, R. Sushmitha, M. Arumugam Pillai
}

10.18805/IJARe.A-5826

\begin{abstract}
Background: Forty two crosses involving seven lines and six testers were studied for economically important yield contributing and quality traits to test the magnitude of genetic components and diversity. Formulation of efficient breeding methodology is possible by targeting the genetic architecture of genotypes.

Methods: The systematic breeding programme involves generating genetic variability besides sorting off the diverse genotypes and utilizing the extreme phenotypes for producing stable varieties. Genetic diversity helps to achieve the greater continuum of genetic variability in segregating populations to reach for ideal selection of progenies. Heritability and genetic advance are other important selection parameters for retrieving better genotype through selection.

Result: Significant differences in analysis of variance were recorded for all the traits. The results signified the greater value of phenotypic coefficient of variation (PCV) than genotypic coefficient of variation (GCV) and environment coefficient of variation (ECV) pertaining to the test traits studied. Among agronomical characters, the GCV and PCV were reported to be in higher estimate for number of productive tillers per plant, number of grains per panicle, single plant yield and among quality characters for gelatinization temperature (GT), length breadth (LB) ratio, gel consistency and amylose content. The present study adverted that among the yield and grain quality characters viz., number of productive tillers, number of grains per panicle, single plant yield, plant height, 1000 grain weight, milling percentage and grain length could be easily inherited to next generation due to high heritability. Whereas breadth elongation ratio and linear elongation ratio are influenced by environmental factors due to their low heritability. Further, the number of productive tillers, number of grains per panicle, single plant yield, plant height, Gel consistency and amylose content exhibited higher PCV, GCV, heritability and genetic advance and hence direct selection can be made for target traits.
\end{abstract}

Key words: Genetic components, Grain quality, First filial crosses, Seed yield.

\section{INTRODUCTION}

Rice (Oryza sativa Linn.) construed as an ideal food for people of Asiatic and African region and is chiefly targeted over 2.5 billion people. In India, rice is a cereal and staple food crop which occupies an area of 43.86 million ha and combats a prioritized task in food security of India contributing 46 per cent of the overall cereal production besides 43 per cent of total food grain production feeding more than 70 per cent population of the country. Globally, India constitutes the largest rice area to the tune of 36.9 million hectares shouldering second in production accounting 120.6 million tonnes. Evolution of rice hybrids exhibiting a productive advantage of 30 per cent compared to the existing hybrids contributed significantly for increasing production and productivity (Sharma et al., 2013). Moreover, the yield potential of hybrids can be increased by improvement in parental lines. Hence, ensuring greater productivity is of prime factor in any breeding experiment. Traits viz., reduced plant height, moderate tillering habit, large and compact panicles, increased number of grains per panicle, increased thousand kernel weight and higher yield construed significant rice characters for any trait based improvement (Ghara et al., 2014). Grain quality is also a major factor to be considered for cooking and eating and
Department of Plant Breeding and Genetics, Agricultural College and Research Institute, Killikulam-628 252, Tamil Nadu, India.

Corresponding Author: S. Saravanan, Department of Plant Breeding and Genetics, Agricultural College and Research Institute, Killikulam-628 252, Tamil Nadu, India.

Email: saravananspbg@tnau.ac.in

How to cite this article: Saravanan, S., Sushmitha, R. and Pillai, M.A. (2022). Elucidation of Genetic Parameters Controlling Yield and Quality Traits in Rice (Oryza sativa L.). Indian Journal of Agricultural Research. DOI: 10.18805/IJARe.A-5826.

Submitted: 19-05-2021 Accepted: 09-12-2021 Online: 07-01-2022

plays a major role in marketing, foreign exchange and consumer preferences to increase the profitability.

Formulation of efficient breeding methodology for trait based improvement is possible by targeting the genetic architecture of genotypes. The systematic breeding programme involves generating genetic variability besides sorting off the diverse genotypes and utilizing the extreme phenotypes for producing stable varieties. Heritability and genetic advance are other important selection parameters for retrieving better genotype through selection. Segregating populations are more important for improving plant types 
by operating selection (Ashish, 2018). Further, it was an established fact that Line $\times$ tester analysis could be an excellent tool for harnessing selection of appropriate progenies in advance generation on target traits (Bhatti et al., 2015).

\section{MATERIALS AND METHODS}

The experiment was conducted at B block farm of Plant Breeding and Genetics, Agricultural College and Research Institute, Killikulam during Kharif 2019. The materials comprised of forty two first filial crosses generated using seven lines (ADT 38, IR 20, ACK 14072, CO 50, CR 1009 SUB1, White ponni and TP 10106), six testers (Thuyamalli, Chandaikar, Norungan, Sivappumalli, ADT 39 and TPS 3). The rice genotypes, IR 20 and CO 39 were used as checks. Recommended agronomic practices were adopted in RBD with replicated thrice adopting a plant and row spacing of $20 \times 20 \mathrm{~cm}$. The biometric values on phenotypic traits viz., plant height $(\mathrm{cm})$, number of productive tillers, number of grains per panicle, panicle length, days for 50 per cent flowering, yield per plant (g), 1000 grain weight (g), milling per cent, head rice recovery, grain length $(\mathrm{cm})$, grain breadth (cm), LAC $(\mathrm{cm}), B A C(\mathrm{~cm})$, LER, BER, Gel consistency, Gelatinization temperature and Amylose content were recorded and their means were utilized for analysis. The phenotypic values were interpreted in WINDOSTAT biometric software to assess genotypic coefficient of variation (\%), phenotypic coefficient of variation (\%), heritability in broad sence (\%), genetic advance and genetic advance as per cent of mean. Variability estimates treated as per the categorization proposed by Sivasubramanian and
Madhava Menon (1973), heritability and genetic advance as per cent of mean were interpreted as per protocol given by Johnson et al. (1955).

\section{RESULTS AND DISCUSSION}

The present study insinuated the existence of significant variations on the test entries for targeted phenotypic traits implicating the presence of greater genetic variability among test crosses which is most ultimate for any crop improvement programme to schedule the selection process efficiently (Table 1). The range of phenotypic value for number of grains per panicle registered as 263 (IR $20 \times$ ADT 39) to 72 (CR 1009 Sub $1 \times$ Norungan) with a general mean of 139.28 followed by plant height as $161 \mathrm{~cm}$ (White ponni $x$ Norungan) to $52.65 \mathrm{~cm}$ (CR1009 Sub $1 \times$ Chandaikar) with a general mean of $99.83 \mathrm{~cm}$. As far as the qualitative traits are concerned, highest phenotypic value was recorded for gel consistency as from 97.4 (IR64) to 27.90 (Co $50 \times$ TPS 3) and had mean value of 69.50 followed by head rice recovery percentage from 84 per cent (White ponni $\times$ Thuyamalli) to 48 per cent (Co50 $\times$ Chandaikar) with a general mean of 66 per cent (Table $2 a$ and $2 b$ )

Genotypic (GCV), phenotypic (PCV) and environmental $(E C V)$ coefficient of variation were calculated for each character and presented in Table 3 . The results signified the greater value of phenotypic coefficient of variation (PCV) than genotypic coefficient of variation (GCV) and environment coefficient of variation (ECV) pertaining to the test traits studied (Chauhan et al., 2020). Among agronomical characters, the GCV and PCV were reported to be in higher estimate for number of productive tillers per

Table 1: Analysis of variance for 19 characters in rice.

\begin{tabular}{lccccccc}
\hline & Replication & Crosses & Line Effect & Tester Effect & Line x Tester Effect & Error & Total \\
\cline { 2 - 7 } df & 2 & 41 & 6 & 5 & 30 & 82 & 125 \\
\hline Plant height & $264.952^{* *}$ & $1409.039^{* *}$ & $7314.966^{* *}$ & $1011.620^{*}$ & $294.090^{* *}$ & 39.381 & 492.238 \\
Number of productive tiller & 0.18 & $173.711^{* *}$ & 196.695 & $617.400^{* *}$ & $95.166^{* *}$ & 3.078 & 58.999 \\
Panicle length & $3.998^{*}$ & $32.817^{* *}$ & 92.170 & $48.376^{*}$ & $18.353^{* *}$ & 1.035 & 11.507 \\
Number of grains per panicle & 40.849 & $6187.943^{* *}$ & $32030.168^{* *}$ & $3234.301^{* *}$ & $1511.771^{* *}$ & 61.986 & 2070.962 \\
Days for 50\% flowering & 14.913 & $547.056^{* *}$ & $2492.630^{* *}$ & $155.475^{*}$ & $223.204^{* *}$ & 20.669 & 193.232 \\
Plant yield & 2.499 & $328.929^{* *}$ & $1474.952^{* *}$ & $246.454^{*}$ & $113.470^{* *}$ & 10.148 & 114.586 \\
1000 grain weight & $1.618^{*}$ & $30.272^{* *}$ & $79.945^{*}$ & $30.206^{*}$ & $20.349^{* *}$ & 0.44 & 10.244 \\
Milling per cent & $12.951^{*}$ & $139.856^{* *}$ & $603.003^{* *}$ & $80.583^{*}$ & $57.106^{* *}$ & 3.456 & 48.347 \\
Head rice recovery & 7.808 & $172.720^{* *}$ & $876.168^{* *}$ & $50.801^{*}$ & $52.350^{* *}$ & 10.127 & 63.42 \\
Grain length & 0.006 & $1.209^{* *}$ & $3.525^{* *}$ & 0.172 & $0.918^{* *}$ & 0.031 & 0.417 \\
Grain breadth & 0.036 & $0.208^{* * *}$ & $0.491^{*}$ & 0.25 & $0.145^{* *}$ & 0.027 & 0.087 \\
LB ratio & 0.082 & $0.705^{* *}$ & $2.706^{* * *}$ & 0.531 & $0.334^{* *}$ & 0.078 & 0.283 \\
Length after cooking & 0.067 & $1.340^{* *}$ & $4.429^{* *}$ & 0.257 & $0.902^{* *}$ & 0.049 & 0.473 \\
Breadth after cooking & 0.035 & $0.194^{* *}$ & $0.424^{*}$ & $0.338^{*}$ & $0.124^{* *}$ & 0.03 & 0.084 \\
Length elongationratio & 0.002 & $0.008^{* *}$ & 0.005 & 0.007 & $0.009^{* *}$ & 0.002 & 0.004 \\
Breadth elongation Ratio & 0.006 & $0.023^{* * *}$ & 0.033 & 0.01 & $0.024^{* *}$ & 0.007 & 0.012 \\
Gelatinization temperature & $0.911^{*}$ & $2.435^{* *}$ & $8.480^{* *}$ & $4.156^{* *}$ & $0.939^{* *}$ & 0.206 & 0.948 \\
Gel consistency & 62.538 & $742.041^{* *}$ & $3655.811^{* *}$ & 293.323 & $234.073^{* *}$ & 25.637 & 261.208 \\
Amylose content (\%) & $21.802^{* *}$ & $52.055^{* *}$ & $244.967^{* *}$ & 38.56 & $15.721^{* * *}$ & 3.76 & 19.889 \\
\hline
\end{tabular}


plant, number of grains per panicle, single plant yield and among quality characters for gelatinization temperature (GT), length breadth (LB) ratio, gel consistency and amylose content. The range of environmental coefficient of variation ranged from 2.29 (Milling per cent) to 13.47 (Gelatinization temperature). The genotypic and phenotypic coefficient of variation registered insignificant variant for most of the test traits investigated except LB ratio, breadth after cooking (BAC) and gelatinization temperature (GT) which was an indication of greater influence of the environment over these three characters. The traits investigated in the present study exhibited moderate and high values of PCV and GCV besides lesser ECV (Perween et al., 2020). Hence, effective and careful phenotypic selection alone will be imperative for effective improvement of these traits. Most of the traits except breadth elongation ratio (41), linear elongation ratio (58), breadth after cooking (65), grain breadth (69), length breadth (74) pronounced higher heritability. Higher level of genetic advance as per cent of mean estimates was registered for grains per panicle (91.12), plant height (43.66), gel consistency (31.82), days to $50 \%$ flowering (27.90), Single plant yield (23.83), head rice recovery (14.02), number of productive tillers (13.61) and milling per cent (13.34).

The greater genetic advance coupled heritability for productive tillers per plant, grains per panicle and seed yield provides greater unswerving note about the efficacy of selection in among target traits in the developed progenies than the control entries. The traits that pronounced greater heritability coupled with higher genetic advance signified the presence of additive gene action and hence be improved through simple or progeny selection, but the characters which exhibited higher heritability coupled with moderate or lower genetic advance can be enhanced by intermating selected superior progenies among segregating population. In the present study, higher heritability associated with higher genetic advance for yield attributing characters was in accordance with the studies pronounced by Sidhya et al. (2014).

The present study adverted that among the yield and grain quality characters viz., number of productive tillers, number of grains per panicle, single plant yield, plant height, 1000 grain weight, milling percentage and grain length could be easily inherited to next generation due to high heritability. Whereas breadth elongation ratio and linear elongation ratio are influenced by environmental factors due to their low heritability. Further, the number of productive tillers, number of grains per panicle, single plant yield, plant height, Gel consistency and amylose content exhibited higher PCV, GCV, heritability and genetic advance and hence direct selection can be made for target traits.

Table 2a: Mean performance of parents for quantitative characters.

\begin{tabular}{|c|c|c|c|c|c|c|}
\hline Parents & $\begin{array}{l}\text { Days to fifty } \\
\text { per cent flowering }\end{array}$ & $\begin{array}{l}\text { Plant height } \\
\qquad(\mathrm{cm})\end{array}$ & $\begin{array}{l}\text { Tillers } \\
\text { per plant }\end{array}$ & $\begin{array}{l}\text { Panicle length } \\
\text { (cm) }\end{array}$ & $\begin{array}{c}\text { Grains } \\
\text { per panicle }\end{array}$ & $\begin{array}{c}\text { Single plant } \\
\text { yield }(g)\end{array}$ \\
\hline & \multicolumn{6}{|c|}{ Lines } \\
\hline ADT 38 & $70.30^{*}$ & $80.91^{*}$ & 14.05 & 21.51 & 76.39 & $47.49^{*}$ \\
\hline IR 20 & $103.60^{*}$ & $96.15^{\star}$ & 14.89 & 21.45 & 105.74 & 22.53 \\
\hline ACK 14072 & $101.60^{*}$ & $80.97^{*}$ & 15.01 & 18.41 & $132.88^{*}$ & 32.76 \\
\hline CO 50 & $96.66^{*}$ & $89.59^{*}$ & 15.39 & $22.80^{\star}$ & 119.27 & 32.36 \\
\hline CR 1009 sub 1 & 126.00 & $53.92^{*}$ & 15.47 & 16.65 & 83.93 & 25.80 \\
\hline White Ponni & 109.00 & 127.59 & $20.02^{*}$ & $22.58^{*}$ & $172.29^{*}$ & $57.91^{*}$ \\
\hline TP 10106 & $63.33^{*}$ & 103.40 & 13.89 & $22.84^{*}$ & 83.14 & 24.77 \\
\hline Mean (L) & 95.83 & 90.36 & 15.54 & 20.89 & 110.52 & 34.81 \\
\hline \multirow[t]{2}{*}{ SEd } & 8.30 & 8.58 & 0.78 & 0.91 & 12.94 & 4.97 \\
\hline & \multicolumn{6}{|c|}{ Testers } \\
\hline Thuyamalli & $91.33^{*}$ & $95.63^{*}$ & 14.49 & 22.59 & $145.34^{*}$ & $41.88^{*}$ \\
\hline Chandaikar & $82.66^{\star}$ & $70.93^{*}$ & $15.55^{\star}$ & 18.78 & 96.17 & 32.81 \\
\hline Norungan & $105.66^{*}$ & 121.26 & 13.26 & 22.5 & 105.74 & 23.45 \\
\hline Sivappumalli & 112.66 & 146.93 & 11.45 & $25.69^{*}$ & 119.15 & 18.36 \\
\hline ADT 39 & 112.33 & $92.32^{*}$ & $15.24^{*}$ & 23.59 & 95.94 & $51.80^{*}$ \\
\hline TPS 3 & $105.66^{*}$ & $98.80^{*}$ & 15.05 & 22.61 & 92.48 & 31.47 \\
\hline Mean $(\mathrm{T})$ & 101.68 & 104.32 & 14.18 & 22.63 & 109.14 & 33.30 \\
\hline SE d & 4.50 & 9.81 & 0.58 & 0.84 & 7.53 & 4.53 \\
\hline CD (0.05) & 8.47 & 7.85 & 0.93 & 1.52 & 10.11 & 1.24 \\
\hline
\end{tabular}

*significance at $5 \%$ level. 


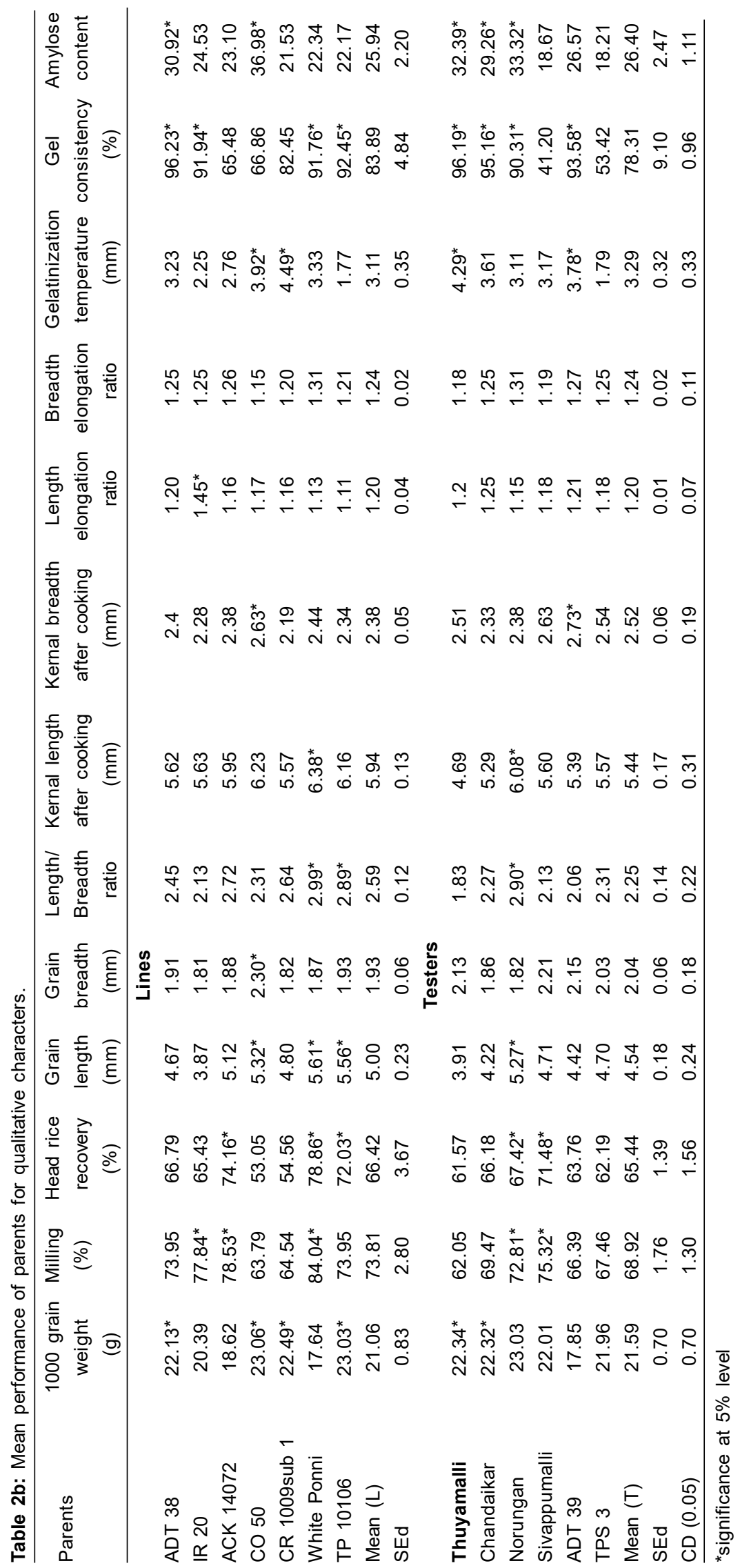


Elucidation of Genetic Parameters Controlling Yield and Quality Traits in Rice (Oryza sativa L.)

Table 3: Genetic variability estimates for varied traits in Rice.

\begin{tabular}{|c|c|c|c|c|c|}
\hline \multirow{2}{*}{ Character } & \multicolumn{3}{|c|}{ Coefficient of variation } & \multirow{2}{*}{$\begin{array}{c}\text { Heritability } \\
\left(\mathrm{h}^{2}\right) \%\end{array}$} & \multirow{2}{*}{$\begin{array}{l}\text { Genetic } \\
\text { advance }\end{array}$} \\
\hline & PCV & GCV & ECV & & \\
\hline Plant height $(\mathrm{cm})$ & 22.69 & 21.92 & 5.89 & 93 & 43.66 \\
\hline Number of productive tillers & 39.89 & 38.88 & 8.91 & 95 & 13.61 \\
\hline Panicle length $(\mathrm{cm})$ & 14.78 & 14.06 & 4.57 & 90 & 5.96 \\
\hline Number of grains per panicle & 32.35 & 31.92 & 5.31 & 97 & 91.12 \\
\hline Days to 50 per cent flowering & 15.69 & 14.91 & 4.88 & 90 & 27.90 \\
\hline Single plant yield (g) & 28.09 & 27.34 & 6.43 & 94 & 23.83 \\
\hline 1000 grain weight $(\mathrm{g})$ & 13.95 & 13.65 & 2.88 & 95 & 5.84 \\
\hline Milling per cent & 9.45 & 9.16 & 2.29 & 94 & 13.34 \\
\hline Head rice recovery $(\%)$ & 11.67 & 10.88 & 4.20 & 87 & 14.02 \\
\hline Grain length $(\mathrm{cm})$ & 13.95 & 13.46 & 3.68 & 93 & 1.22 \\
\hline Grain breadth $(\mathrm{cm})$ & 14.64 & 12.18 & 8.12 & 69 & 0.39 \\
\hline LB ratio & 20.22 & 17.50 & 10.13 & 74 & 0.77 \\
\hline Length after cooking & 11.86 & 11.21 & 3.86 & 89 & 1.20 \\
\hline Breadth after cooking & 11.61 & 9.39 & 6.81 & 65 & 0.36 \\
\hline Linear elongation ratio & 5.99 & 4.58 & 3.86 & 58 & 0.08 \\
\hline Breadth elongation ratio & 8.26 & 5.31 & 6.32 & 41 & 0.08 \\
\hline Gelatinization temperature & 31.24 & 28.18 & 13.47 & 81 & 1.59 \\
\hline Gel consistency & 20.54 & 19.81 & 0.73 & 96.43 & 31.82 \\
\hline Amylose (\%) & 20.29 & 19.15 & 1.14 & 94.38 & 8.72 \\
\hline
\end{tabular}

\section{REFERENCES}

Ashish, G. (2018). Studies on genetic variability for yield and yield traits in rice (Oryza sativa L.). Intl J. Plant Sci. (Muzaffarnagar). 13(1): 188-191.

Bhatti, S., Pandey, D. and Singh, D. (2015). Combining ability and heterosis for yield and its component traits in rice [Oryza sativa (L.)]. Elect J. of PI. Breeding. 6(1): 12-18.

Chauhan, S., Sitole, R., Dawar, S., Dhakad, R. and Hatila, S. (2020). Evaluation of genetic variability of rice (Oryza sativa L.) germplasm for growth and yield contributing traits. J. Pharmacogn Phytochem. 9(1): 226-228.

Ghara, A.G., Nematzadeh, G., Bagheri, N., Oladi, M. and Bagheri, A. (2014). Heritability and heterosis of agronomic traits in rice lines. Intl. J. Farm. and Alli. Sci. 3(1): 66-70.

Johnson, H.W., Robinson, H.F. and Comstock, R.E. (1955). Estimation of genetic and environmental variability in soybeans. Agron. J. 47: 314-318.
Perween, S., Anand Kumar, S.P. Singh, Mankesh and Mankesh Kumar, R.R. (2020). Genetic variability parameters for yield and yield related traits in rice (Oryza sativa L.) under irrigated and drought stress condition. Int. J. Curr. Microbiol. App. Sci. 9(2): 1137-1143.

Sharma, C., Singh, N., Mall, A., Kumar, K. and Singh, O. (2013). Combining ability for yield and yield attributes in rice (Oryza sativa L.) genotypes using CMS system. SAARC J. Agric. 11(1): 23-33.

Sidhya, P., Koundinya, A. and Pandit, M. (2014). Genetic variability, heritability and genetic advance in tomato. Environ. Ecol. 32(4B): 1737-1740.

Sivasubramanian, S and Madhava Menon, P. (1973). Genotypic and phenotypic variability in rice. Madras Agri. Journal. 60: 1093-1096. 